\title{
85 yaş üstü hastalarda endoskopik retrograd kolanjiyopankreatografi'nin etkinliği ve güvenilirliği
}

\author{
Safety and efficacy of endoscopic retrograde cholangiopancreatography in patients aged $\geq 85$ years
}

\author{
(D) Mustafa KAPLAN ${ }^{1}$, (D Bülent ÖDEMIŞ², (D) Selçuk DişiBEYAZ³ , (D Volkan GÖKBULUT ${ }^{2}$, (D) Orhan COŞKUN ${ }^{4}$, \\ (D) Adem AKSOY 5
}

Kayseri Memorial Hastanesi, ${ }^{1}$ Gastroenteroloji Klinį̆i, Kayseri Ankara Bilkent Şehir Hastanesi, ${ }^{2}$ Gastroenteroloji Kliniği, Ankara Osmangazi Üniversitesi Tip Fakültesi, ${ }^{3}$ Gastroenteroloji Kliniği, Eskişehir Amasya Devlet Hastanesi, ${ }^{4}$ Gastroenteroloji Klinižri, Amasya

Nevşehir Devlet Hastanesi, ${ }^{5}$ Gastroenteroloji Kliniği, Nevşehir

\begin{abstract}
Giriş ve Amaç: Bu çalışmada 85 yaş üstü hastalarda endoskopik retrograd kolanjiyopankreatografinin endikasyonları, bulguları, başarısı ve komplikasyonları araştırıldı. Gereç ve Yöntem: Bu çalışmada 2015-2019 yılları arasında endoskopik retrograd kolanjiyopankreatografi yapılan hastaların kayıtlarn incelenmiş ve çalışma 85 yaş üzeri 289 hasta ile yapılmıştır. Bulgular: Çalışma 169 kadın (\%58) ve 120 erkek (\%42) olmak üzere toplam 289 hasta ile yapılmısstır. Hastaların ortalama yaşı 88 idi (85-108). Endoskopik retrograd kolanjiyopankreatografinin en sık endikasyonları izole karaciğer enzim yüksekliği (\%39), kolanjit (\%32) ve karaciğer enzim yüksekliği olmaksızın karın ağrısıydı (\%21). Hastaların \%66'sına yatırlarak, \%87.2'sine sadece tek seans endoskopik retrograd kolanjiyopankreatografi yapılmıștı. Hastaların \%28'inde divertikül mevcuttu ve \%25'i sfinkterotomiliydi. Hastaların \%99'u ilk seansta, tamamı ise ikinci seansta kanülize edildi. 241 hastada selektif (\%83), 48 hastada precut (\%16) yöntemi kullanıldı. En sık endoskopik retrograd kolanjiyopankreatografi bulguları koledok taș (\%71) ve malign biliyer darlıktı (\%12). En sık görülen maligniteler ise pankreas kanseri (\%38) ve kolanjiyokanserdi (\%32). Taş çıkanlarda teknik başarı \%99, malign hastalarda ise \%100 idi. Çalışmamızda en sık görülen komplikasyonlar post-endoskopik retrograd kolanjiyopankreatografi pankreatiti (\%5.8) ve kanama (\%2) idi. Bir hastada tip l perforasyon gelişti ve hasta exitus oldu. Üç yılllk takipte mortalite oranı $\% 26$ iken 30 günlük mortalite oranı $\% 8$ olarak bulunmuştur. Sonuç: Eşlik eden kronik hastalıklara rağmen, 85 yaş ve üstü hastalarda endoskopik retrograd kolanjiyopankreatografi güvenli ve etkili bir tedavi yöntemidir.
\end{abstract}

Anahtar kelimeler: Geriatri, safra kanalı taşları, endoskopik retrograd kolanjiyopankreatografi

\section{GİRISS}

Yaşam beklentisi ve tıbbi bakımdaki sürekli iyileştirmelerle, yaşlanan nüfusla ilişkili sorunlar ülkemizde giderek önem kazanmaktadır (1). Yaşlı hastalarda pankreatobiliyer hastalıkların insidansı artmaktadır (2). Özellikle 75 yaşın üzerindeki hastalarda, safra kanalı taşları ve kanser tüm sarılık vakalarının \% 70'ini oluşturmaktadır (3). Bu durum kolelitiazis, koledokolitiyazis ve ilerleyen yaşla birlikte malignite prevalanslarının artmasıyla ilişkilidir. Endoskopik retrograd ko-
Background and Aims: We investigated the indications, findings, and success and complication rates using endoscopic retrograde cholangiopancreatography in patients aged $\geq 85$ years. Materials and Methods: The study included 289 patients aged $\geq 85$ years. The records of patients who had undergone endoscopic retrograde cholangiopancreatography between 2015 and 2019 were examined. Results: The study population included 169 females (58\%) and 120 males (42\%) with a mean age of 88 years (range, 85-108 years). The most common indications for endoscopic retrograde cholangiopancreatography were isolated liver enzyme level elevation (39\%), cholangitis (32\%), and abdominal pain without elevated liver enzyme levels $(21 \%)$. Of the total, $66 \%$ patients were hospitalized and $87.2 \%$ patients required only 1 endoscopic retrograde cholangiopancreatography session. Diverticulum was present in 28\% patients, and 25\% had prior sphincterotomy. Cannulation in the first session was performed for 99\% patients and in the second session for the remaining. Of the total, selective method was used in 241 patients (83\%) and precut method in 48 patients (16\%). The most common endoscopic retrograde cholangiopancreatography findings included choledochal stone (71\%) and malignant biliary stenosis (12\%). The most common malignancies included pancreatic cancer (38\%) and cholangiocarcinoma (32\%). A 99\% technical success was achieved in patients with stone, which was $100 \%$ in patients with malignancy. The most common complications included post- endoscopic retrograde cholangiopancreatography pancreatitis $(5.8 \%)$ and bleeding $(2 \%)$. One patient experienced type 1 perforation and died. The 30-day mortality rate was 8\%, which increased to $26 \%$ at the 3-year follow-up. Conclusion: Despite concomitant chronic diseases, endoscopic retrograde cholangiopancreatography is a safe and effective treatment for patients aged $\geq 85$ years.

Key words: Geriatrics, bile duct stones, endoscopic retrograde cholangiopancreatography

lanjiyopankreatografi (ERCP), bu pankreatobiliyer hastalıklar için iyi bilinen bir terapötik araçtır. ERCP özellikle safra yollarında taş ve periampuller bölge tümörlerinin hem tanısında hem de tedavisinde önemli bir yer tutmaktadır (4).

Bununla birlikte, terapötik ERCP invaziv bir prosedürdür ve ERCP'nin akut pankreatit, perforasyon, kanama ve kolanjit gibi çok ciddi komplikasyonları olabilmektedir (5). Özellikle 
80 yaşın üzerindeki hastalarda sıklıkla kardiyovasküler hastalıklar, nörolojik hastalıklar ve akciğer hastalıkları gibi eşlik eden tıbbi bozukluklar olması nedeniyle bu komplikasyonların ve mortalitenin yaşlılarda çok daha fazla olacağı düşünülmektedir.

Yaşlı hastalarda ERCP'nin güvenliği ve etkinliği hakkında daha önceki birçok rapora rağmen (6-8), gerçek klinik uygulamada 85 yaşın üzerindeki hastalarda ERCP'nin komplikasyonları ile ilgili endişe vardır. Bu nedenle bu çalışmada 85 yaş üstü hastalarda ERCP'nin etkinliğini, güvenilirliğini ve komplikasyonlarını tek bir merkezde değerlendirmeyi amaçladık.

\section{GEREC ve YÖNTEM}

Bu çalışma 2015-2019 yllları arasında hastanemizde ERCP yapılan hastaların kayıtları incelenerek retrospektif olarak yapılmıştır. Toplamda 5780 hasta dosyası incelenmiş, 85 yaş üzerinde toplam 304 hasta bulunmuştur. 6 hasta veri eksikliği nedeniyle çalışmadan dışlanmıştır. Ayrıca üç hastada apikal darlık, üç hastada malign infiltrasyon ve üç hastada Billroth 2 ve Braun anastomozu olması nedeniyle ERCP yapılamadı ve bu hastalar çalışmaya alınmadı. Çalışma 289 hasta ile yapılmıştır. Hastaların işlem endikasyonları, işlem sırasindaki Amerikan Anesteziyologlar Birliği (ASA) skoru, yatış yapılıp yapılmadığı, ERCP seans sayıları ve ERCP bulguları dosyalardan kaydedilmiştir.

Hastalar aşağıda belirtilen ASA skoruna (9) göre sınıflanmıştır:

1. Normal sağlıklı hasta (ASA 1)

2. Hafif sistemik hastalığı olan hasta (ASA 2)

3. Ciddi sistemik hastalığı olan hasta, günlük aktiviteleri etkilemeyen (ASA 3)

4. Hayati tehlike yaratan ciddi sistemik hastalığı olan hasta (ASA 4)

5. Ameliyatsız yaşam ümidi olmayan, ölümcül hasta (ASA 5)

ERCP endikasyonları 5 ana grupta incelendi: Karaciğer fonksiyon testleri (KCFT) yüksekliği olmaksızın karın ağrısı, kolanjit olmaksızın KCFT yüksekliği, kolanjit, biliyer pankreatit ve biliyer kaçak.

Tüm ERCP işlemleri midozalam ve petidin altında anestezi ile deneyimli iki endoskopist tarafından yapılmıştır. Işlemler için Olympus TJF 260V markalı duedonoskop (Olympus, Tokyo, Japan) kullanıldı. Koledok ve dalların görüntülenmesi için balon oklude kolanjiyogram alındı. Safra yollarında taş görülen hastalara balon ile lavaj ve gerektiğinde basket ile tas kırma işlemi uygulandı. Safra yolları drenajı gerekli olduğunda hastaların skopik ve klinik durumları göz ününe alınarak plastik veya metalik stentler veya nazobiliyer drenaj kullanıl- dı. Işlem için üç kanülizasyon yöntemi belirlendi: Selektif, prekut ve randevu yöntemi.

ERCP'de safra taşı olanlarda teknik başarı taşın tamamen çıkartılması olarak kabul edildi. Malign hastalarda ise stent takabilme teknik başarı olarak kabul edildi. Diğer hasta gruplarında ise kaçağın kaybolması ve safra drenajının sağlanması teknik başarı olarak kabul edildi.

Işleme bağlı komplikasyonlar mevcut ERCP kılavuzları göz önüne alınarak kaydedildi. Başlıca 5 komplikasyon kaydedildi: post-ERCP Pankreatit (PEP), sızdırır tarzda hafif kanama, işlem gerektirecek kanama, kolanjit ve perforasyon. Takip süresince mortalite gelişip gelişmediği ulusal veri bankası taranarak kaydedildi. Isşlem sonrası 30 gün içerinde gerçekleşen mortalite işleme bağlı komplikasyon olarak kabul edildi.

Istatistiksel değerlendirme Statistical Package for Social Sciences (SPSS) for Windows 20 (IBM SPSS Inc., Chicago, IL) programı kullanılarak yapılmıştır. Verilerin normal dağılımı Kolmogorov-Smirnov testi ile değerlendirilmiștir. Sayısal değişkenlerden normal dağılım sergileyenler ortalama \pm standart sapma olarak, normal dağılım sergilemeyenler ortanca (min-max) olarak gösterilmiştir. Kategorik değişkenler sayı ve yüzde olarak belirtilmiştir.

Çalışma retrospektif olduğu için hastalardan yazılı onam alınmadı. Çalışma, 1964 Helsinki Deklarasyonu'nda belirtilen etik standartlara göre yürütüldü. Çalışmamızda araştırma ve yayın etiği takip edildi ve kurallara uyuldu. Çalışmanın etik onayı 22.02.2018 tarih ve 34 sayı numarasıyla Türkiye Yüksek Ihtisas Eğitim ve Araştırma Hastanesi etik kurulundan alınmıştır.

\section{BULGULAR}

Çalışma 169 kadın (\%58) ve 120 erkek (\%42) olmak üzere toplam 289 hasta ile yapılmıştır. Hastaların ortalama yaşı 88.7 idi (85-108). Hastaların ASA skorları incelendiğinde 99 hastanın skoru 2 (\%34), 145 hastanın skoru 3 (\%50) ve 45 hastanın skoru 4 idi (\%16). ERCP'nin en slk endikasyonlan izole KCFT yüksekliği (\%39), kolanjit (\%32) ve KCFT yüksekliği olmaksızın karın ağrısı (\%21) olarak bulunmuştur. Hastaların \%66'sına yatırılarak işlem yapılmıştı ve ortalama yatış süresi 12 gündü (1-75 gün ). Hastaların \%87.2'sine sadece tek seans ERCP yapılmıştı. Birden fazla seans ERCP yapilanlarda en sık sebepler ise kolanjit (\%36), zor taş (\%23), uluslararası normalleştirilmiş oran (INR) yüksekliği veya antiagregan kullanımı (\%13), işlem sonrası kanama (\%10) ve midenin dolu olmasıydı (\%10). Ilk seansta kanülize edilemeyen üç hasta ikinci seansta başarılı bir şekilde kanülize edildi (\%8). Hastaların demografik özellikleri, ASA skorları, işlem endikasyonları, yatıs bilgileri ve ERCP seans sayıları Tablo l'de özetlenmiştir. 
Tablo 1. Demografik özellikler, ASA skorları, işlem endikasyonları, yatış bilgileri ve ERCP seans sayıları

\begin{tabular}{|c|c|}
\hline Değişkenler & n (\%) \\
\hline Yaş (ortalama) & $88.7(85-108)$ \\
\hline Cinsiyet (kadın/erkek) & $169(\% 58) / 120(\% 42)$ \\
\hline $\begin{array}{l}\text { ASA skorları } \\
2 \\
3 \\
4\end{array}$ & $\begin{array}{c}99(\% 34) \\
145(\% 50) \\
45(\% 16)\end{array}$ \\
\hline $\begin{array}{l}\text { Endikasyon } \\
\text { Karın ağrısı (enzim yüksekliği yok) } \\
\text { Izole KCFT yüksekliği (kolanjit yok) } \\
\text { Kolanjit } \\
\text { Biliyer pankreatit } \\
\text { Biliyer kaçak }\end{array}$ & $\begin{array}{l}60(\% 21) \\
112(\% 39) \\
93(\% 32) \\
23(\% 8) \\
1(\% 0.03)\end{array}$ \\
\hline Yatış & $192 / 289(\% 66)$ \\
\hline Yatış gün (ortalama) & $12(1-75)$ \\
\hline $\begin{array}{l}\text { ERCP seans sayısı } \\
\text { Tek seans } \\
\text { Birden fazla seans (2 veya 3) } \\
\text { Kolanjit } \\
\text { Zor taş } \\
\text { INR yüksekliği-antiagregan alımı } \\
\text { Isslem sonrası kanama } \\
\text { Dolu mide } \\
\text { Başarısız kanülizasyon (2. deneme ) }\end{array}$ & $\begin{array}{c}250(\% 87) \\
39(\% 13) \\
14(\% 36) \\
9(\% 23) \\
5(\% 13) \\
4(\% 10) \\
4(\% 10) \\
3(\% 8)\end{array}$ \\
\hline
\end{tabular}

KCFT: Karaciğer fonksiyon testi, ERCP: Endoskopik retrograd kolanjiyopankreotografi, INR: International normalized ratio.

Hastaların ERCP bulguları Tablo 2'de verilmiştir. Hastaların $\% 28$ 'inde divertikül mevcuttu. Hastaların büyük çoğunluğunda koledok dilate olarak izlendi (\%95). Hastaların \%25'inin daha önceden sfinkterotomili (EST'li) olduğu görüldü. Daha önceden EST'li bu hastalardan 5'ine EST yetersiz olduğu için re-EST yapıldı (\%2). 5 hastaya ise INR yüksekliği ve antigregan kullandığı için papil naif olmasına rağmen EST yapılmadı. Kalan 213 hastaya EST yapıldı (\%74). Hastaların \%99'u ilk seansta, tamamı ise ikinci seansta kanülize edildi. 241 hastada selektif kanülizasyon kullanılırken (\%83) 48 hastada precut (\%16) ve iki hastada randevu yöntemi kullanılmıştır (\%1). Hastaların ERCP bulguları incelendiğinde 206 hastada koledok taşı saptandı (\%71). 34 hastada malign biliyer darlık (\%12), 7 hastada benign biliyer darlık (\%2), 6 hastada mirizzi sendromu (\%2), iki hastada biliyer kaçak (\%1) ve iki hastada koledok kisti saptandı (\%1). 32 hastada ise hiçbir patoloji saptanmadı (\%11). En sık görülen maligniteler ise pankreas kanseri (\%38) ve kolanjiyokanserdi (\%32). İşlem sırasında hastaların \%40'nna stent takılmıştı ve stentlerin büyük çoğunluğu plastik stent idi (\%80). En sık kullanılan plastik stent
Tablo 2. ERCP bulguları

Değişkenler

n (\%)

ERCP'de divertikül oranı

$82 / 289(\% 28)$

Koledok dilate mi?

273/289 (\%95)

EST var mi?

$71 / 289(\% 25)$

EST yapilma durumu

EST yapıldı

$213 / 289(\% 74)$

Tekrar EST yapılmadı

$66 / 289(\% 23)$

EST'li ama re-EST yapıldı

$5 / 289(\% 2)$

Naif papil ama koagülopatiden dolayı

EST yapılmadı

$5 / 289(\% 2)$

Kanülizasyon yöntemleri

Selektif

241/289 (\%83)

Precut

48/289 (\%16)

Fistülotomi

34

Konvansiyonel

11

Transpankreatik septotomi

Randevu

1

2/289 (\%1)

Sonuçlar

Taş

206/289 (\%71)

Malign biliyer darlık

$34 / 289$ (\%12)

$13 / 34(\% 38)$

Pankreas kanseri

$11 / 34(\% 32)$

$7 / 34(\% 21)$

2/34 (\%6)

$1 / 34(\% 3)$

Metastatik mide kanseri

$32 / 289(\% 11)$

Temiz

$7 / 289(\% 2)$

$6 / 289(\% 2)$

2/289 (\%1)

$2 / 289(\% 1)$

Biliyer kaçak

$116 / 289(\% 40)$

Stent takılma durumu

93/116 (\%80)

Plastik stent

6

$7 \mathrm{~F}$ düz

58

$10 \mathrm{~F}$ düz

9

7 F DP

21

Metalik stent

20/116 (\%17)

NBD

$3 / 116(\% 3)$

Kullanılan ek yöntemler

Balon dilatasyonu

$50 / 289$ (\%17)

Basket ve mekanik litrotripsi

25/289 (\%9)

Spyglass

$1(\% 0.3)$

ERCP: Endoskopik retrograd kolanjiyopankreotografi, EST: Endoskopik sfinkterotomi, F: French, DP: Double pigtail, NBD: Nazobiliyer dren.

tipleri ise $10 \mathrm{~F}$ düz veya double pigtail stentlerdi. Darlık veya taşı olan hastalarda kullanılan diğer endoskopik yöntemler ise balon dilatasyonu (\%17), basket ile mekanik litotripsi (\%9) ve spyglass ile taşların kııılmasıdır (\%0.3). 
ERCP'nin başarısı, komplikasyonlar ve mortalite oranları Tablo 3'te verilmiştir. Çalışmamızda kanulizasyon başarısı \%100 olarak bulunmuştur. ERCP'de taş çıkan hastalarda taşın temizlenme başarısı birinci seansta \%91, ikinci seansta \%98 ve üçüncü seansta \%99 olarak bulunmuştur. Malignite tanısı alan hastalarda stent takabilme olarak tarif ettiğimiz teknik başarı oranı ise \%100 olarak bulunmuştur. Çalışmamızda en sık görülen komplikasyon post-ERCP pankreatittir (\%5.8). $\mathrm{Bu}$ hastaların hepsi medikal tedavi ile tamamen düzelmiştir. Ikinci sık görülen komplikasyon ise kanamadır. 4 hastada kendiliğinden duran sızdırır kanama görülürken (\%1.3) 4 hastada tekrar işlem gerektiren kanama oldu (\%1.3). Bu 4 hastanın üçüne heater uygulaması ve adrenalin ile skleroterapi, birine ise metalik stent konularak kanama kontrolü sağlandı. Bir hastada tip 1 perforasyon gelişti ve hasta exitus oldu. Üç yıllık takipte mortalite oranı \%26 iken 30 günlük mortalite oranı \%8 olarak bulunmuştur.

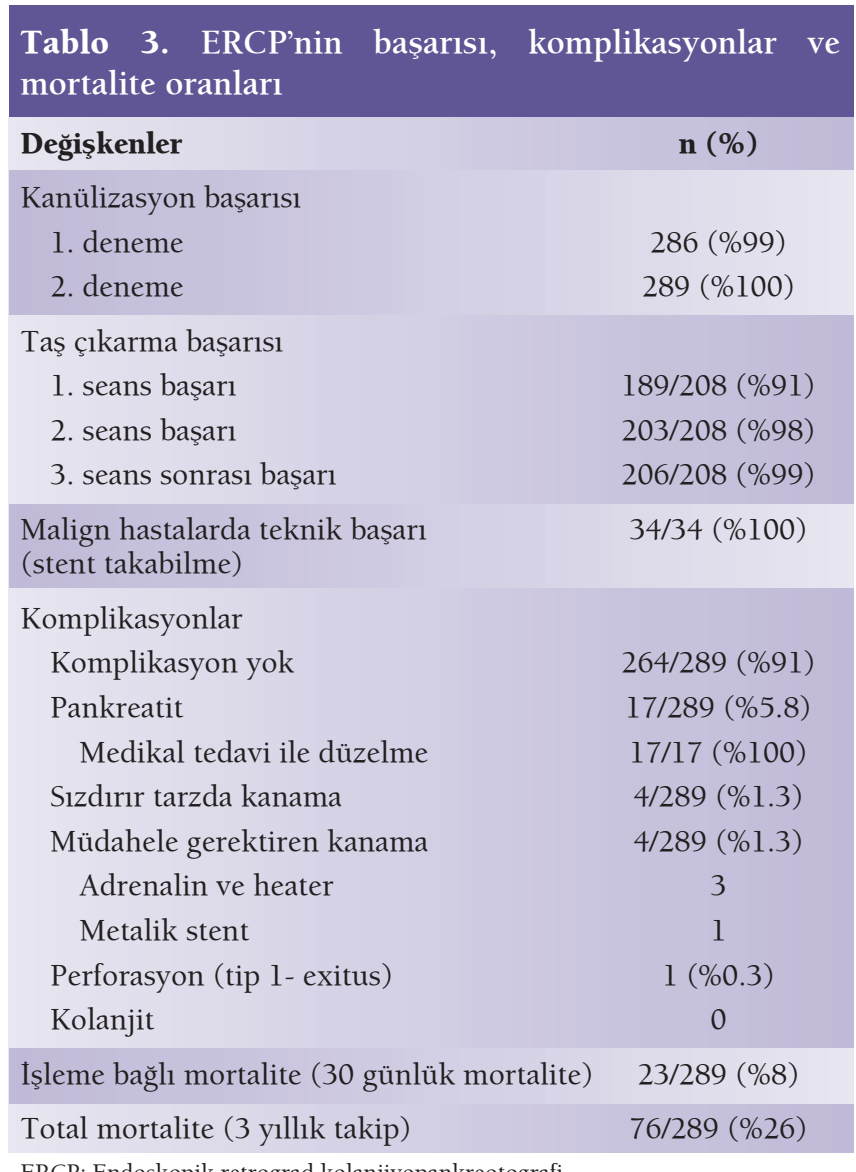

ERCP: Endoskopik retrograd kolanjiyopankreotografi.

\section{TARTISSMA}

Erken tanı yöntemlerinin gelişmesi ve etkin tedaviler ile ortalama beklenen yaşam süresi dünyanın bir çok yerinde 70 hatta 80 yaşın üzerine çıkmıştır. Bu nedenle geriatrik hastalarda birçok konu son zamanlarda literatürde çokca incelenmektedir. Bu konulardan biri de yaşlı hastalarda ERCP'nin etkinliği ve güvenilirliğidir. Bu çalışmada 85 yaş üzerindeki hastalarda ERCP'nin başta koledok taşı ve malignite tedavisinde etkin bir tedavi yöntemi olduğu, işlemin teknik başarısının yüksek olduğu ve genel popülasyona benzer oranda yan etkilere sahip olduğu gösterilmiştir.

Bizim çalışmamız literatürde 85 yaş üstündeki hastalarda ERCP'yi araştıran en geniş katılımlı çalışmalardan biridir. Yang ve ark.nın çalışması 141 hasta ile, Han ve ark.nın çalışması ise 312 hasta ile yapılmıştır $(3,4)$. Çalışma popülasyonları incelendiğinde ortalama yaşam süresi daha uzun olduğundan ERCP ihtiyacının kadınlarda daha çok olduğunu gördük. En yaşlı hastamız ise 108 yaşında idi. Hastalarımızın ASA skorları incelendiğinde tamamen sağlıklı hastamızın hiç olmadığı, çoğu hastanın skorunun iki veya üç olduğu görülmektedir. Kolanjite bağlı organ yetmezliği veya ek komorbid durumları olanlarda ise skor 4 idi. Garcia ve ark.nın çalışmasında da bizim çalışmamıza benzer skorlar vardı (10). Aynı çalışmada hastaların nerdeyse tamamına yatırılarak işlem yapıldı ̆̆ görülmektedir. Bizim çalışmamızda ise hastaların yatırılma oranı \%66 idi. Hastalarımızın ortalama yatış süresi 12 gün idi. Köklü ve ark.nın çalışmasında ise bu süre 14 gündü (11). Genel olarak bakıldığında yaşlı hastalarda ERCP işleminin yatırılarak yapılmasının daha güvenli olduğunu söyleyebiliriz.

Kim ve ark.nın çalışmasında ortalama ERCP seans sayısının yaş arttıkça arttığı belirtilmiştir ve 80 yaş üstü hastalarda bu oran 1.38 olarak bulunmuştur (12). Bizim çalışmamızda ise yukarıdaki çalışmanın aksine olarak hastaların çoğuna tek seans işlem yapılmış olup ortalama seans sayısı 1.17 olarak bulunmuştur. Aslında yaşlı hastalarda komorbid durumlar ve aspirin gibi ilaçlar kullanılması nedeniyle daha fazla işlem seansı beklenirken bizim çalışmamızda çoğu hastanın işlemleri tek seansta bitirilmiştir. Birden fazla ERCP gerektiren işlemlerde en önemli sebepler ise şiddetli kolanjit, tam sfinkterotomi yapılamaması, papilin kanülize edilememesi veya komplikasyon olması gibi beklenen durumlardır.

Yang ve ark.nın çalışmasında periampuller divertikül oranı 80 yaşın üzerindeki hastalarda \%30, 65 yaşın üzerindeki hastalarda ise \%20 olarak bulunmuştur (4). Bizim çalışmamızda ise bu oran \%28 olarak bulunmuştur. Divertikül olmasının klinik olarak anlamı ise bu hastalarda ERCP'nin daha zor olması ve perforasyon riskinin daha fazla olabilmesidir. Ama bizim çalışmamızda beklenenin aksine sadece bir hastada perforasyon görülmüştür. Çalışmamızdaki hastaların dörtte birinin sfinkterotomili olduğu görülmüştür. 465 hasta ile yapılan bir çalışmada yine benzer şekilde hastaların \%27'sinin sfinkterotomili olduğu görülmüştür (13). Çalışmamızda kanülizasyon başarımız \%100 idi. Çoğu hasta selektif kanülize edilirken bazen precut ve randevu yöntemleri de kullanılmıştır. Behlül ve ark.nın çalışmasında kanülizasyon başarısı ise benzer şekilde \%98 olarak bulunmuştur (14). 
Çalışmamızdaki hastaların en sık endikasyonları; enzim yüksekliği olmaksızın karın ağrısı, kolanjit olmaksızın izole KCFT yüksekliği ve kolanjit idi. Bu bulgularımız literatür ile uyumlu idi. Garcia ve ark.nın çalışmasındaki en sık endikasyonlar ise karın ağrısı, enzim ve bilüribin yüksekliği, kolanjit ve pankreatit idi (10). ERCP'nin iki tipik endikasyonu safra kanalı taşları veya malignitenin neden olduğu safra tıkanıklığıdır. Her iki durum da yaşla birlikte artar. Nitekim bizim çalışmamızda bu iki endikasyon vakaların \%83'lük kısmını oluşturmaktaydı. Hastalarımızın \%1l'lik kısmında ise ERCP sonucu temiz çıktı. Bu durumun en olası nedenleri ise atılmış taş ve işlem öncesi görüntüleme yöntemlerinin eksikliği olabilir. Çalışmamızda malign biliyer darlık saptanan hastaların etiyolojisinde en sık pankreas kanseri ve kolanjiyokanser olduğu görülmüştür. Köklü ve ark.nın çalışmasında da en sık malign biliyer darlık sebebi olarak pankreas kanseri bulunmuştur (11). Diğer bir çalışmada ise bizim bulgularımıza benzer şekilde en sık malign darlık sebebi pankreas kanseri iken ikinci sırada kolanjiyokanser gelmekteydi (14).

Çalışmamızda teknik başarı malign darlığı olan hastalarda \%100 iken koledok taşı olanlarda ise \%99 olarak bulunmuştur. Han ve ark.nın çalışmasında teknik başarı \%94.9 olarak bulunmuştur (3). Yang ve ark.nın çalışmasında ise \%92 olarak bulunmuştur (4). Çalışmamızda tüm hastalar başarılı bir şekilde kanülize edilmiştir. Koledok taşı olanlarda taşların tamamen temizlenmesi olarak tarif edilen teknik başarı bizim çalışmamızda üçüncü seans sonucunda \%99 olarak bulunmuştur. Taşı temizlenmeyen iki hasta ise takipte başka bir nedenden dolayı exitus olmuştur. Muratta ve ark.nın çalışmasında taşların tamamen temizlenmesi oranı bizim çalışmamıza benzer şekilde \%99 bulunmuştur (15). Malign safra darlıkları ERCP'nin yaygın görülen endikasyonlarındandır. Tedavi seçenekleri ise plastik veya metalik biliyer stentlerin yerleştirilmesini içerir. Bizim çalışmamızda malign darlığı olan tüm hastalarda bu stentler ile safra akışı sağlanmış ve dolayısıyla teknik başarı \%100 olarak bulunmuştur. Daha önceki çalışmalarda bizim çalışmamıza benzer şekilde malign biliyer darlı̆̆ı olanlarda ERCP'nin etkin bir yöntem olduğu gösterilmiştir (16).

ERCP'nin komplikasyonları incelendiğinde Han ve ark.nın çalıșmasında tüm komplikasyon oranı \%4.8, Yang ve ark. nın çalıșmasında \%6.5, Garcia ve ark.nın çalıșmasında ise \%6.2 olarak bulunmuştur $(3-4,10)$. Bizim çalıșmamızda ise bu oran \%8.7 olarak bulunmuştur. Oranın yüksek olmasının nedeni ise bizim çalışmamızda aslında klinik olarak önemsiz olan kanamaların da komplikasyon olarak kabul edilmesi olduğunu düşünüyoruz.

PEP ERCP'nin en slk ve ciddi komplikasyonudur. Bildirilen yaygınlı \%1.3 ile \%8 arasında değişmektedir (17). Bizim çalışmamızda ise PEP oranı \%5.8 olarak bulunmuştur. Eşlik eden çok sayıda ek hastalık ve yaş faktörüne rağmen PEP oranının çok fazla olmaması yaşlı hastalarda ERCP'nin PEP açısından güvenli olduğunu göstermektedir. Ayrıca PEP gelişen bu hastaların hepsi medikal tedavi ile iyileşmiştir. Bu da aslında ek komorbid durumlar nedeniyle daha kötü seyretmesi beklenen PEP'in aslında çok da korkutucu olmadığını göstermiştir.

Bizim çalışmamızda ikinci en sık görülen komplikasyon kanama olarak bulunmuştur. Ama komplikasyon gelişen tüm hastalar başarılı bir şekilde tedavi edilmiştir. Bu nedenle kanama kaynaklı herhangi bir mortalite olmamıştır. Kanama kontrolünde adrenalin ile skleroterapi, heater uygulaması ve gerektiğinde metalik stent takılması çok başarılı olmuştur. Literatürde sfinkterotomi sonrası kanama insidansı \%0.76 ile \%2 arasında değişmektedir (18). Oranların bizim çalışmamızda daha yüksek olmasının sebebi ise bizim çalışmamızda müdahele gerektirmeyen kanamaların da çalışmaya alınmış olmasıdır. Yine de hastaların ek komorbid durumları olması, bazı hastaların INR'sinin yüksek olması ve klopidogrel veya asetilsalisilik asit gibi ilaçlar almasına rağmen majör bir kanama olmaması nedeniyle bu hasta grubunda ERCP'nin kanama açısından güvenli olduğunu söyleyebiliriz.

Önceki çalışmalarda ERCP sonrası perforasyon oranları \%0.3 ile \%0.6 arasında değişmektedir (19). Bizim çalışmamızda ise sadece bir hastada perforasyon gelişmiştir. Bu hastaya metalik stent takılmıs ama mortaliteye engel olunamamıştır. Bu hasta grubunda özellike divertikül oranının yaşla birlikte arttığı düşünüldüğünde perforasyon görülmesi beklenen bir durumdur.

Çalışmamızdaki direkt işleme bağlı sadece bir hastada mortalite görünmesine rağmen işleme bağlı olarak kabul ettiğimiz 30 günlük mortalite oranı \%8 olarak bulunmuştur. Daha önceki çalışmalarda bu oran \%1-5 arasında bulunmuştur (20). Ayrıca hastaların 3 ylllık takipte nerdeyse üçte biri ölmüştür. $\mathrm{Bu}$ durumun en olası nedeni hasta grubumuzun çok yaşlı hastalardan oluşması idi. Ayrıca hastalarda birçok ek komorbid hastalığın olması ve bazı hastalara kolanjit nedeniyle ERCP yapılması nedeniyle böyle bir sonuç elde edildiğini düşünüyoruz.

Çalısmamızın en önemli kısıtllı̆ı̆ı retrospektif yapılmış olmasıdır. Diğer bir önemli kısıtllılk ise hasta sayısının az olmasıdir.

Sonuç olarak yaşlı hastalarda yüksek oranda eşlik eden kronik hastalıklar görülmesine rağmen, 85 yaş ve üstü hastalarda ERCP güvenli ve etkili bir müdahaledir.

\section{"Tüm yazarlar bu makalenin yayınlanmasında çıkar çatış- ması olmadığını deklare ederler."}

Finansal Destek: Yazarlar bu çalışma için finansal destek almadıklarını beyan etmişlerdir. 
Çalışma retrospektif olduğu için hastalardan yazılı onam alınmadı. Çalışma, 1964 Helsinki Deklarasyonu'nda belirtilen etik standartlara göre yürütüldü. Çalışmamızda araștırma ve yayın etiği takip edildi ve kurallara uyuldu. Çalışmanın etik onayı 22.02.2018 tarih ve 34 sayı numarasıla Türkiye Yüksek İhtisas Eğitim ve Araștırma Hastanesi etik kurulundan alınmıştır.

\section{KAYNAKLAR}

1. Pitkälä KH, Martin FC, Maggi S, Jyväkorpi SK, Strandberg TE. Status of Geriatrics in 22 Countries. J Nutr Health Aging 2018;22:627-31.

2. Corrigan LR, Bracken-Clarke DM, Horgan AM. The challenge of treating older patients with pancreaticobiliary malignancies. Curr Probl Cancer 2018;42:59-72.

3. Han SJ, Lee TH, Kang BI, et al. Efficacy and safety of therapeutic endoscopic retrograde cholangiopancreatography in the elderly over 80 years. Dig Dis Sci 2016;61:2094-101.

4. Yang JH, Li W, Si XK, Zhang JX, Cao YJ. Efficacy and safety of therapeutic ERCP in the elderly: A single center experience. Surg Laparosc Endosc Percutan Tech 2018;28:e44-8.

5. Guda NM, Reddy DN, Kumar A. Complications of ERCP. Indian J Gastroenterol 2014;33:1-9.

6. Lukens FJ, Howell DA, Upender S, Sheth SG, Jafri SM. ERCP in the very elderly: outcomes among patients older than eighty. Dig Dis Sci 2010;55:847-51

7. Kalaitzakis E. All-cause mortality after ERCP. Endoscopy 2016;48:98794.

8. Saito H, Koga T, Sakaguchi M, et al. Safety and efficacy of endoscopic removal of common bile duct stones in elderly patients $\geq 90$ years of age. Intern Med 2019;58:2125-32.

9. Owens WD, Felts JA, Spitznagel EL. ASA physical status classificationsdstudy of consistency of ratings. Anesthesiology 1978;49:239-43.

10. Garcia CJ, Lopez OA, Islam S, et al. Endoscopic retrograde cholangiopancreatography in the elderly. Am J Med Sci 2016;351:84-90.

11. Köklü S, Parlak E, Yüksel O, Sahin B. Endoscopic retrograde cholangiopancreatography in the elderly: a prospective and comparative study. Age Ageing 2005;34:572-7.

12. Kim JE, Cha BH, Lee SH, et al. Safety and efficacy of endoscopic retrograde cholangiopancreatograpy in very elderly patients. Korean J Gastroenterol 2011;57:237-42.

13. Galeazzi M, Mazzola P, Valcarcel B, et al. Endoscopic retrograde cholangiopancreatography in the elderly: results of a retrospective study and a geriatricians' point of view. BMC Gastroenterol 2018;18:38.

14. Baydar B, Serin A, Vatansever S, et al. Safety of endoscopic retrograde cholangiopancreatography in patients 80 years of age and older. Prz Gastroenterol 2014;9:227-31.

15. Murata A, Motomura Y, Akahoshi K, et al. Therapeutic ERCP for choledocholithiasis in patients 80 years of age and older. J Clin Gastroenterol 2009; 43:289-90

16. Bill JG, Mullady DK. Stenting for benign and malignant biliary strictures. Gastrointest Endosc Clin N Am 2019;29:215-35.

17. Fritz E, Kirchgatterer A, Hubner D, et al. ERCP is safe and effective in patients 80 years of age and older compared with younger patients. Gastrointest Endosc 2006;64:899-905

18. Masci E, Toti G, Mariani A, et al. Complications of diagnostic and therapeutic ERCP; a prospective multicenter study. Am J Gastroenterol 2001;96:417-23.

19. Loperfido S, Angelini G, Benedetti G, et al. Major early complications from diagnostic and therapeutic ERCP; a prospective multicenter study. Gastrointest Endosc 1998;48:1-10

20. Søreide JA, Karlsen LN, Sandblom G, Enochsson L. Endoscopic retrograde cholangiopancreatography (ERCP): lessons learned from population-based national registries: a systematic review. Surg Endosc 2019;33:1731-48. 